\title{
Otolith geochemistry discriminates among estuarine nursery areas of Solea solea and S. senegalensis over time
}

\author{
S. E. Tanner ${ }^{1, *}$, P. Reis-Santos ${ }^{1}$, R. P. Vasconcelos ${ }^{1}$, S. França ${ }^{1}$, S. R. Thorrold ${ }^{2}$, \\ H. N. Cabral ${ }^{1}$ \\ ${ }^{1}$ Centro de Oceanografia, Faculdade de Ciências da Universidade de Lisboa, Campo Grande, 1749-016 Lisbon, Portugal \\ ${ }^{2}$ Biology Department, Woods Hole Oceanographic Institution, Woods Hole, Massachusetts 02543, USA
}

\begin{abstract}
Otolith geochemistry is used increasingly as a natural tag to retrospectively determine habitat use in marine fishes. It is necessary to first conduct a thorough assessment of spatiotemporal variability before attempting to use the approach to determine estuarine residency or natal origins. In particular, knowledge of temporal variation at different scales is important when such variability may confound spatial discrimination. We assayed elements and calculated the elemental ratios to $\mathrm{Ca}(\mathrm{Li}: \mathrm{Ca}, \mathrm{Mg}: \mathrm{Ca}, \mathrm{Mn}: \mathrm{Ca}, \mathrm{Cu}: \mathrm{Ca}, \mathrm{Sr}: \mathrm{Ca}, \mathrm{Ba}: \mathrm{Ca}, \mathrm{Pb}: \mathrm{Ca}$ ) in otoliths of juvenile Solea solea and Solea senegalensis, collected over several months in 2006 and 2009 in Portuguese estuaries, using laser ablation inductively coupled plasma mass spectrometry (LA ICP-MS). The elemental compositions of the otoliths varied significantly between and within years in both of the species, although the within-year variability did not interfere in spatial discrimination. The overall classification accuracy of juveniles to their estuaries of origin varied among the years and species, ranging from 71.0 to $80.1 \%$. Established elemental signatures constitute the baseline data for future assessments of connectivity between juvenile and adult populations of the 2 sole species.
\end{abstract}

KEY WORDS: Otolith chemical composition · Temporal variability · Soleidae · Connectivity · Natural tags

Resale or republication not permitted without written consent of the publisher

\section{INTRODUCTION}

Movement of individuals among geographically separated subpopulations, or connectivity, is an essential component of the understanding of fish population dynamics, colonization patterns and resilience to harvesting (Cowen et al. 2007). Many marine fishes undertake movements among habitats at different times during their life history cycle. For instance, juveniles often use estuaries as nursery grounds before recruiting to adult populations offshore. Knowledge of these movement patterns can contribute significantly to the identification of ecologically important habitats, the sustainable manage- ment of fish populations and the design of marine protected areas (Thorrold et al. 2007).

Quantifying the movement of fishes is a difficult undertaking that, over the decades, has been tackled using a variety of indirect approaches, including comparison of the distribution, abundance and size structure of study species as well as artificial and natural tagging methods (reviewed by Gillanders et al. 2003). Conventional tagging methodologies are logistically difficult to execute due to the small size, high mortality rates and low recapture rates of juveniles. Hence, natural tags have become more commonly used, and in particular, otolith geochemistry has developed into a promising technique to quantify 
rates of movement (Thorrold et al. 2002, Elsdon et al. 2008). Otoliths are useful natural tags due to their continuous growth and metabolic inertness and the fact that the incorporation of at least some elements is influenced by environmental conditions, while other elements are under physiological or genetic control (Campana 1999). Otoliths have been widely used in age structure and growth studies and, more recently, to estimate population structure (e.g. Campana 1999, Thresher \& Procter 2007), assess migration patterns (Hamer et al. 2006, Fairclough et al. 2011), identify natal origin or nursery areas (Vasconcelos et al. 2007b, Clarke et al. 2009) and retrospectively classify adults to their areas of origin (e.g. Thorrold et al. 2001, Vasconcelos et al. 2008).

Otolith geochemistry must show significant spatial variation among the areas of interest for otoliths to be effectively used as natural tags in population connectivity studies. Variability at the appropriate temporal scales may also need to be investigated because several studies have shown differences in otolith composition among years (Gillanders 2002, Kerr et al. 2007) and within years (Thorrold et al. 1998, Hamer et al. 2003). Information on temporal variation, particularly the inter-annual stability of otolith geochemistry, is necessary for retrospective determination of adult origins. Furthermore, variation at smaller time scales, e.g. among seasons, may confound spatial discrimination, leading to misinterpretation of geochemical data. The discriminatory power of otolith geochemistry in estuarine systems along the Portuguese coast and their applicability in connectivity studies has already been demonstrated (Vasconcelos et al. 2007b, 2008). However, little is known about the inter-annual stability of otolith geochemistry from marine migrant species along the Portuguese coast, and temporal variation at smaller scales has yet to be investigated.

The common sole, Solea solea (Linnaeus, 1758), and the Senegalese sole, Solea senegalensis Kaup, 1858, are flatfishes of commercial importance throughout Europe. Their distribution is sympatric from the Bay of Biscay to Senegal and the western Mediterranean Sea (Quéro et al. 1986). The 2 species are very similar in terms of morphology and ecology. Spawning and larval development takes place in shelf waters with metamorphosis, and the resulting shift to a benthic life form occurs during transport from spawning to nursery grounds (Marchand 1991). Several cohorts of $S$. solea colonize Portuguese estuaries beginning in May, whereas estuarine colonization by $S$. senegalensis starts later and lasts longer (June to October) (Cabral 2003). Juveniles of both species spend up to $2 \mathrm{yr}$ in estuarine nursery grounds before migrating to shelf waters (Quéro et al. 1986, Koutsikopoulos et al. 1989), where they reach sexual maturity at 3 to $4 \mathrm{yr}$ of age (Ramos 1982). The Portuguese coast has several estuaries with well-established nurseries for juveniles of $S$. solea and S. senegalensis (Cabral et al. 2007, Vasconcelos et al. 2010). Within an estuary, juveniles of both species are known to occur in a single nursery area or in multiple, segregated nursery areas (Vasconcelos et al. 2010).

The main objectives of the present study are to (1) determine the temporal variation in otolith composition of the 2 species between and within years and assess its implications on the spatial separation and classification of juveniles to their estuaries of origin, (2) evaluate differences in otolith geochemistry between the 2 sole species and (3) assess the accuracy of the classification of juveniles to their estuaries of origin to use the data as a baseline for future retrospective determination of estuary origin of adult Solea solea and $S$. senegalensis.

\section{MATERIALS AND METHODS}

\section{Sampling surveys and otolith analysis}

Juvenile Solea solea and S. senegalensis were collected in May and July 2006 and in May, July and October 2009 in the main estuarine nursery areas where these species occur along the Portuguese coast (Fig. 1, Table 1). In total, 7 estuaries were sampled: Douro, Ria Aveiro, Mondego, Tejo, Sado, Mira and Guadiana. The main geomorphologic and hydrologic characteristics of these estuarine systems were described by Cabral et al. (2007), and the anthropogenic pressures in these estuaries were explored by Vasconcelos et al. (2007a). In some of the estuarine systems, juveniles of $S$. solea and $S$. senegalensis occur in high densities in 2 or 3 distinct nursery areas; hence, juveniles were collected in all of the areas within a system (Vasconcelos et al. 2010). Individuals obtained from multiple nursery sites within an estuary were pooled because the spatial level of interest in the present study was the estuary scale. Several measurements of water temperature $\left({ }^{\circ} \mathrm{C}\right)$ and salinity were taken during sampling surveys at each collection site using a portable multi-parameter instrument (YSI 6820) and averaged for each collection location and sampling date (Table 2). Fish were collected with a beam trawl, stored and transported on ice to the laboratory and preserved frozen until dissection. The total length of each individual was determined (Table 1), and sagittal otoliths were 


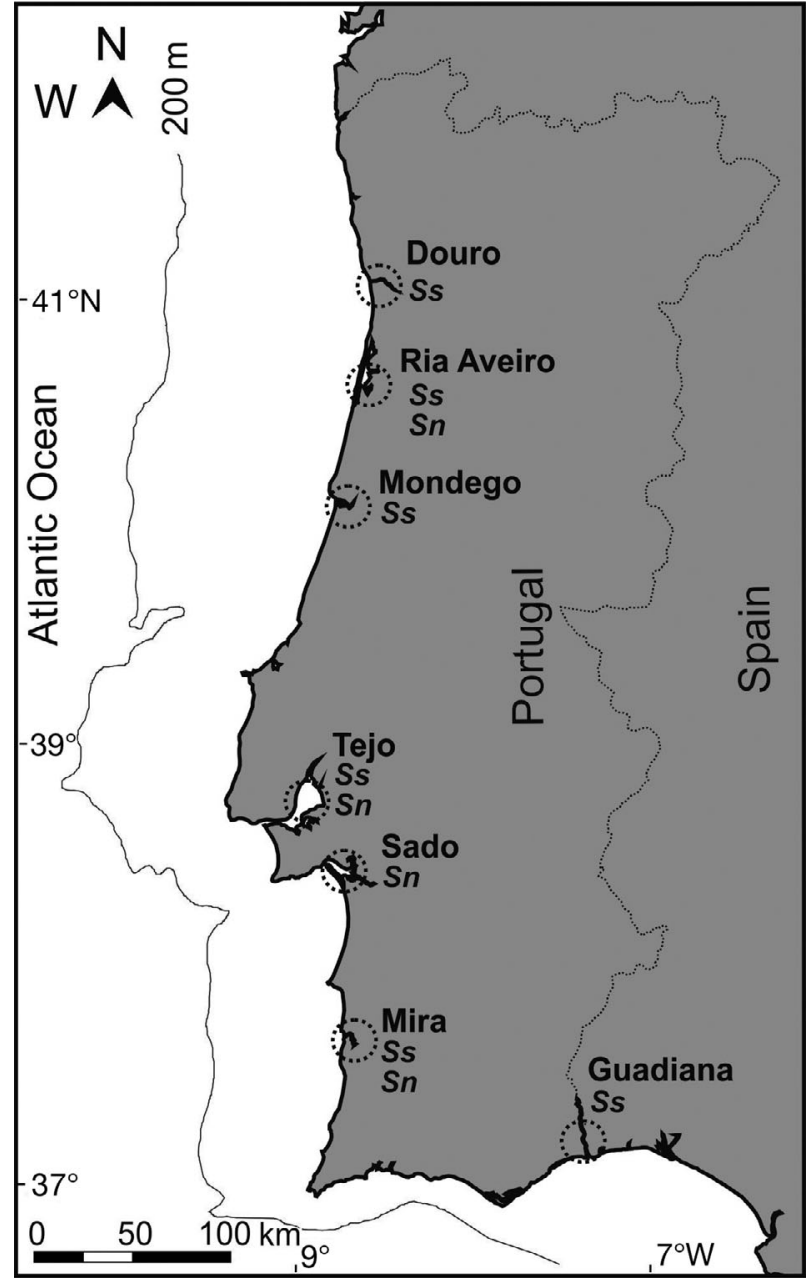

Fig. 1. Occurrence of Solea solea (Ss) and S. senegalensis $(\mathrm{Sn})$ in estuaries sampled along the Portuguese coast in 2006 and 2009 removed, cleaned of adhering tissue and dried. Right otoliths were mounted on glass slides with cyanoacrylic glue and ground to the midplane using $30 \mu \mathrm{m}$ and $3 \mu \mathrm{m}$ lapping film. Surface contamination was removed by immersing the otoliths in ultrapure water, sonicating for $2 \mathrm{~min}$ and triple-rinsing with ultrapure water in a class-100 clean room.

Otoliths were analyzed for $\mathrm{Li}: \mathrm{Ca}, \mathrm{Mg}: \mathrm{Ca}, \mathrm{Mn}: \mathrm{Ca}$, $\mathrm{Cu}: \mathrm{Ca}, \mathrm{Sr}: \mathrm{Ca}, \mathrm{Ba}: \mathrm{Ca}$ and $\mathrm{Pb}: \mathrm{Ca}$ on a Thermo Finnigan Element2 single collector inductively coupled plasma mass spectrometer (ICP-MS) coupled to a New Wave $193 \mathrm{~nm}$ excimer laser ablation system. The laser software was used to trace $450 \mu \mathrm{m}$ lines along the posterior, dorsal edge of the otoliths. The ablated material was transported via a He gas stream to the dual-inlet quartz spray chamber, where it was mixed with a $2 \% \mathrm{HNO}_{3}$ aerosol from a self-aspirating perfluoroalkoxy (PFA) $20 \mu \mathrm{l} \mathrm{min}^{-1}$ nebulizer. The analyte was then transported to the ICP-MS via an Ar carrier gas.

Elemental ratios were quantified by measuring ${ }^{7} \mathrm{Li}$, ${ }^{25} \mathrm{Mg},{ }^{48} \mathrm{Ca},{ }^{55} \mathrm{Mn},{ }^{63} \mathrm{Cu},{ }^{88} \mathrm{Sr},{ }^{138} \mathrm{Ba}$ and ${ }^{208} \mathrm{~Pb}$ in the ablated otolith material. ${ }^{7} \mathrm{Li}$ was not quantified in the otoliths of juvenile Solea solea collected in July 2006. Instrumental blanks $\left(2 \% \mathrm{HNO}_{3}\right)$ were run at the beginning and end of each set of 10 otoliths. A blank correction of all of the measured raw values was done by calculating a blank value for each sample by linear interpolation of the measured blanks. A dissolved otolith certified reference material (CRM) (Sturgeon et al. 2005), diluted to a Ca concentration of $40 \mu \mathrm{g} \mathrm{g}^{-1}$, was used to correct for instrument mass bias. The instrument precision was assessed by running another CRM (Yoshinaga et al. 2000), similarly

Table 1. Sampled estuaries, mean and standard error (SE) of fish total length $\left(L_{t}\right)$ in mm and sample size (n) of juveniles of Solea solea and S. senegalensis along the Portuguese coast during 2006 and 2009

\begin{tabular}{|c|c|c|c|c|c|c|c|c|c|c|c|c|c|c|c|}
\hline \multirow[t]{3}{*}{ Estuary } & \multicolumn{6}{|c|}{-2006} & \multirow{2}{*}{\multicolumn{3}{|c|}{ May }} & \multicolumn{3}{|c|}{2009} & \multirow{2}{*}{\multicolumn{2}{|c|}{ October }} & \multirow[b]{2}{*}{ - } \\
\hline & & May & - & 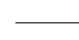 & uly - & & & & & & July & - & & & \\
\hline & $L_{\mathrm{t}}$ & SE & $\mathrm{n}$ & $L_{\mathrm{t}}$ & SE & $\mathrm{n}$ & $L_{\mathrm{t}}$ & $\mathrm{SE}$ & $\mathrm{n}$ & $L_{\mathrm{t}}$ & $\mathrm{SE}$ & $\mathrm{n}$ & $L_{\mathrm{t}}$ & $\mathrm{SE}$ & $\mathrm{n}$ \\
\hline \multicolumn{16}{|l|}{ S. solea } \\
\hline Douro (D) & - & - & - & 77.3 & 2.2 & 12 & 50.2 & 2.5 & 15 & 83.7 & 2.0 & 15 & 111.9 & 7.0 & 15 \\
\hline Ria Aveiro (RA) & 61.8 & 10.2 & 4 & 91.1 & 4.6 & 18 & 41.6 & 2.0 & 15 & - & - & - & - & - & - \\
\hline Mondego (Mo) & 58.2 & 2.2 & 15 & 77.2 & 1.8 & 30 & 51.9 & 4.3 & 20 & - & - & - & - & - & - \\
\hline Tejo (T) & 45.5 & 3.0 & 15 & 88.5 & 2.7 & 15 & 66.6 & 3.7 & 33 & 76.0 & 3.9 & 11 & 89.8 & 4.0 & 15 \\
\hline Mira (Mi) & 37.8 & 0.9 & 31 & 76.9 & 1.5 & 28 & 47.0 & 2.0 & 7 & 85.7 & 2.6 & 25 & 95.6 & 2.0 & 24 \\
\hline Guadiana (G) & 77.6 & 10.1 & 9 & 83.5 & 3.0 & 14 & 45.1 & 2.7 & 13 & 78.4 & 1.6 & 15 & 106.8 & 2.3 & 15 \\
\hline \multicolumn{16}{|l|}{ S. senegalensis } \\
\hline Ria Aveiro (RA) & - & - & - & 73.1 & 3.6 & 20 & - & - & - & 57.8 & 7.3 & 13 & 60.2 & 7.9 & 5 \\
\hline Tejo (T) & 109.3 & 5.8 & 6 & - & - & - & 49.2 & 1.0 & 26 & 74.2 & 3.4 & 21 & 56.4 & 5.6 & 18 \\
\hline Sado (S) & 50.1 & 1.6 & 15 & 86.5 & 3.4 & 26 & 47.2 & 2.1 & 34 & 74.6 & 2.3 & 39 & 57.9 & 4.0 & 26 \\
\hline Mira (Mi) & - & - & - & - & - & - & - & - & - & 69.3 & 15.3 & 6 & 101.0 & 6.1 & 6 \\
\hline
\end{tabular}


Table 2. Temperature and salinity (mean \pm SE) in the estuarine systems sampled along the Portuguese coast in 2006 and 2009

\begin{tabular}{|c|c|c|c|c|c|c|c|c|c|c|}
\hline \multirow{3}{*}{ Estuary } & \multicolumn{4}{|c|}{2006} & \multicolumn{4}{|c|}{2009} & \multirow{3}{*}{$\begin{array}{l}\text { Salinity } \\
\text { July }\end{array}$} & \multirow[b]{3}{*}{ October } \\
\hline & \multicolumn{2}{|c|}{ Temperature $\left({ }^{\circ} \mathrm{C}\right)$} & \multicolumn{2}{|c|}{ Salinity } & \multicolumn{3}{|c|}{ Temperature $\left({ }^{\circ} \mathrm{C}\right)$} & \multirow[b]{2}{*}{ May } & & \\
\hline & May & July & May & July & May & July & October & & & \\
\hline Douro & $17.1 \pm 0.1$ & $24.1 \pm 0.2$ & $1.2 \pm 0.3$ & $10.1 \pm 0.5$ & $18.3 \pm 0.1$ & $23.7 \pm 0.2$ & $19.8 \pm 0.0$ & $2.0 \pm 0.3$ & $2.4 \pm 0.5$ & $2.2 \pm 0.4$ \\
\hline Ria Aveiro & $23.8 \pm 3.1$ & $24.9 \pm 0.2$ & $16.3 \pm 1.3$ & $27.6 \pm 0.2$ & $16.7 \pm 0.2$ & $24.9 \pm 0.3$ & $19.6 \pm 0.1$ & $20.9 \pm 2.3$ & $30.1 \pm 0.7$ & $19.8 \pm 0.6$ \\
\hline Mondego & $20.5 \pm 0.2$ & $23.4 \pm 0.2$ & $6.8 \pm 0.4$ & $15.1 \pm 1.3$ & $19.1 \pm 0.2$ & $22.7 \pm 0.2$ & - & $8.1 \pm 1.2$ & $5.4 \pm 1.0$ & - \\
\hline Tejo & $20.0 \pm 0.1$ & $25.5 \pm 0.1$ & $9.8 \pm 0.5$ & $13.5 \pm 1.1$ & $15.7 \pm 0.3$ & $21.5 \pm 0.3$ & $21.5 \pm 0.2$ & $25.1 \pm 0.8$ & $18.6 \pm 1.1$ & $5.1 \pm 0.1$ \\
\hline Sado & $21.7 \pm 0.2$ & $26.0 \pm 0.1$ & $25.5 \pm 0.4$ & $29.3 \pm 0.7$ & $15.3 \pm 0.7$ & $25.5 \pm 0.6$ & $22.2 \pm 0.2$ & $30.7 \pm 0.8$ & $28.8 \pm 0.3$ & $29.0 \pm 1.3$ \\
\hline Mira & $21.7 \pm 0.2$ & $26.9 \pm 0.1$ & $6.9 \pm 1.0$ & $13.7 \pm 1.0$ & $19.1 \pm 0.0$ & $25.7 \pm 0.1$ & $23.4 \pm 0.0$ & $12.8 \pm 0.5$ & $21.5 \pm 0.9$ & $27.4 \pm 0.3$ \\
\hline Guadiana & $23.1 \pm 0.2$ & $27.0 \pm 0.2$ & $6.9 \pm 1.5$ & $8.9 \pm 1.3$ & $19.8 \pm 0.6$ & $25.4 \pm 0.0$ & $22.0 \pm 0.1$ & $12.8 \pm 1.2$ & $14.7 \pm 0.7$ & $14.2 \pm 0.5$ \\
\hline
\end{tabular}

dissolved and diluted to a Ca concentration of $40 \mu \mathrm{g}$ $\mathrm{g}^{-1}$. The external precision (relative standard deviation) for this reference material $(\mathrm{n}=122)$ was as follows: Li:Ca: 1.9, Mg:Ca: 3.5, Mn:Ca: 12.4, Cu:Ca: 8.6, Sr:Ca: 0.5, Ba:Ca: 2.0 and Pb:Ca: $25.3 \%$.

\section{Data analysis}

The raw data for each element:Ca ratio were $\log _{10}$ transformed to achieve normality and homogeneity of variance-covariance matrices. Differences in otolith elemental composition between and within years were evaluated using multivariate analysis of variance (MANOVA). Inter-annual variation was addressed using estuary and year as factors, and short-term variability was investigated using estuary and month as factors. For the MANOVA tests, Wilks' lambda was used as the test statistic. Elemental differences at these temporal scales were investigated by considering subsets of the data for both Solea solea and S. senegalensis independently. Variation between years was evaluated considering all estuaries sampled in both years, and the 2 months sampled in both years (May and July) were pooled. The assessment of seasonal variability (months) for both species was based on datasets that included estuaries sampled in at least 2 months during the 2009 sampling survey. Canonical discriminant analysis (CDA) was then used to display the multivariate data in reduced space when the MANOVA found significant effects of location or time. An additional CDA was carried out to evaluate otolith chemistry differences between the 2 sole species in estuaries where they co-occurred, based on samples collected in 2009.

Linear discriminant function analysis (LDFA) was used to classify juveniles of the 2 sole species to their estuary of origin. After $\log _{10}$ transformation, the element:Ca ratios met the assumptions of LDFA, i.e. normality and homogeneity of variance-covariance matrices. The classification accuracy of the discriminant functions was evaluated by calculating crossvalidated classification success using a jackknife (leave-one-out) approach. Otolith elemental data from all of the sampled months within each year were pooled for the LDFAs, and all of the estuaries sampled were included in this analysis. October was included in the data of 2009 to ensure that the elemental signatures used in the analysis encompassed all of the assessed temporal variability within an estuary. We subsequently pooled the 4 northern and central estuaries (Douro, Ria Aveiro, Mondego and Tejo) for Solea solea collected in 2006, based on weaker results for these data.

\section{RESULTS}

Significant differences were found in the otolith elemental composition of the 2 sole species among the different temporal scales (between and within years). The range of values of the different element:Ca ratios was similar in the 2 years considered,

Table 3. MANOVA: temporal variation of otolith elemental signatures (a) between years and (b) within one year for Solea solea and $S$. senegalensis. $\mathrm{p}<0.001$ for all comparisons shown

\begin{tabular}{|lrrrr|}
\hline \multicolumn{4}{c}{ S. solea } & \multicolumn{3}{c|}{ S. senegalensis } \\
& df & $F$ & df & $F$ \\
\hline \multicolumn{5}{l}{ a) Between-years comparison; } \\
Estuary & 2006 & and & 2009 \\
Year & 30 & 28.1 & 14 & 7.9 \\
Estuary $\times$ Year & 6 & 7.0 & 7 & 7.7 \\
& 30 & 7.5 & 14 & 5.0 \\
b) Within-year comparison; & 2009 & & \\
Estuary & 21 & 24.7 & 7 & 14.6 \\
Month & 14 & 12.5 & 7 & 2.3 \\
Estuary $\times$ Month & 42 & 3.6 & 28 & 5.2 \\
\hline
\end{tabular}


both in Solea solea and $S$. senegalensis (Fig. 2). No significant correlations were found between the fish total length and element:Ca ratio in either of the years or species.

Both of the sole species showed significant inter-annual variation in otolith elemental composition (Table 3a). For Solea solea, each of the estuaries sampled in 2 years was generally separated in the CDA (Fig. 3a). Only the Guadiana estuary showed overlap of the $95 \%$ confidence ellipses of the mean. The separation of the estuaries and years on the first canonical variate was mainly based on differences in $\mathrm{Mn}: \mathrm{Ca}$, while $\mathrm{Mg}$ :Ca contributed most to the separation on the second canonical variate. Inter-annual variability was also observed in the otolith elemental composition of $S$. senegalensis, with the 2 years separated in Ria Aveiro and Sado (Fig 3b). The Tejo estuary showed some overlap between the 2006 and 2009 data. Separation on the first and second canonical variates was driven by $\mathrm{Ba}: \mathrm{Ca}$ and $\mathrm{Mg}: \mathrm{Ca}$ values, respectively. Regarding the spatial separation of S. solea, the Douro, Ria Aveiro, Mondego and Tejo estuaries occupied similar canonical space, especially in 2006, while clearly separated from the Mira and Guadiana estuaries (Fig. 3a). In the case of $S$. senegalensis, samples from Ria Aveiro and Sado were in close proximity to each other in both years (Fig. 3b). Both of the sole species showed generally higher Mn:Ca values in 2006 in the estuaries where the species occurred (Fig. 2), while $S$. senegalensis otoliths had higher $\mathrm{Li}: \mathrm{Ca}$ and $\mathrm{Mg}$ :Ca ratios in 2009 in all of the estuaries sampled (Fig. 2b). Furthermore, Mn:Ca ratios were noticeably higher in the Mira

Fig. 2. Mean and standard error of element: $\mathrm{Ca}$ ratios $(\mathrm{Li}, \mathrm{Mg}, \mathrm{Mn}, \mathrm{Cu}, \mathrm{Sr}, \mathrm{Ba}, \mathrm{Pb})$ in otoliths of juvenile (a) Solea solea and (b) $S$. senegalensis in the estuarine systems sampled in 2006 and 2009. Data from May and July were pooled in each year. See Table 1 for estuary abbreviations
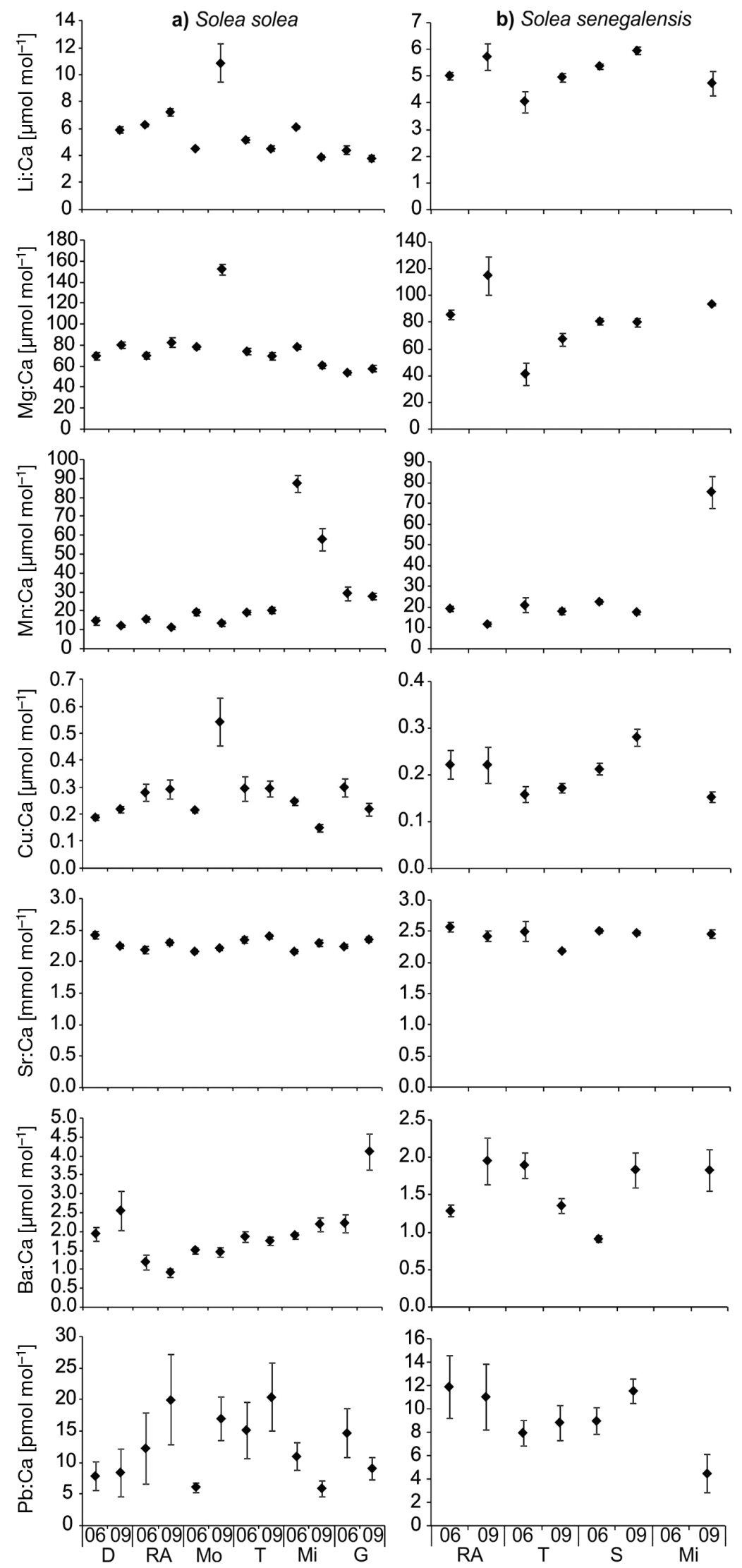
a) S. solea

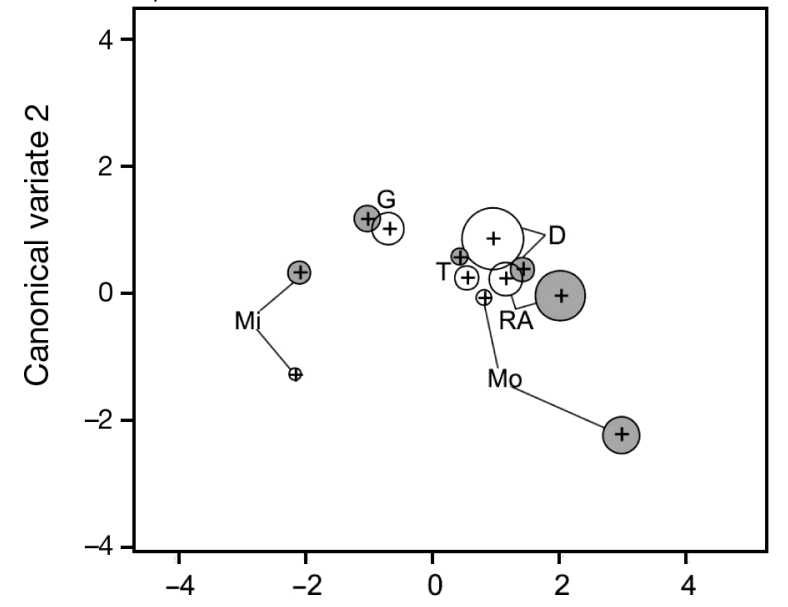

b) S. senegalensis

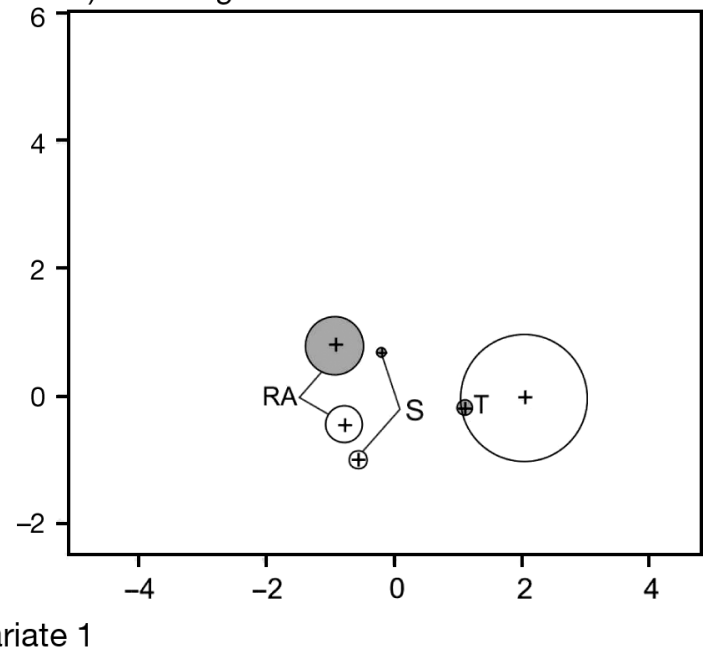

Fig. 3. Canonical discriminant analysis summarizing variation in otolith elemental signatures of juvenile (a) Solea solea and (b) S. senegalensis in the estuarine systems along the Portuguese coast in 2006 (white circles) and 2009 (grey circles). Circle enclosures represent $95 \%$ confidence limits for the mean. See Table 1 for estuary abbreviations

a) S. solea

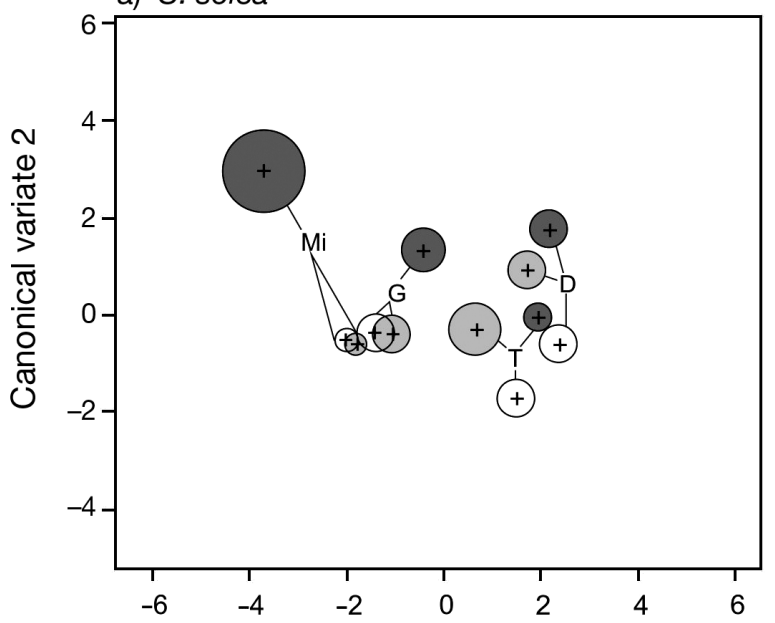

b) S. senegalensis

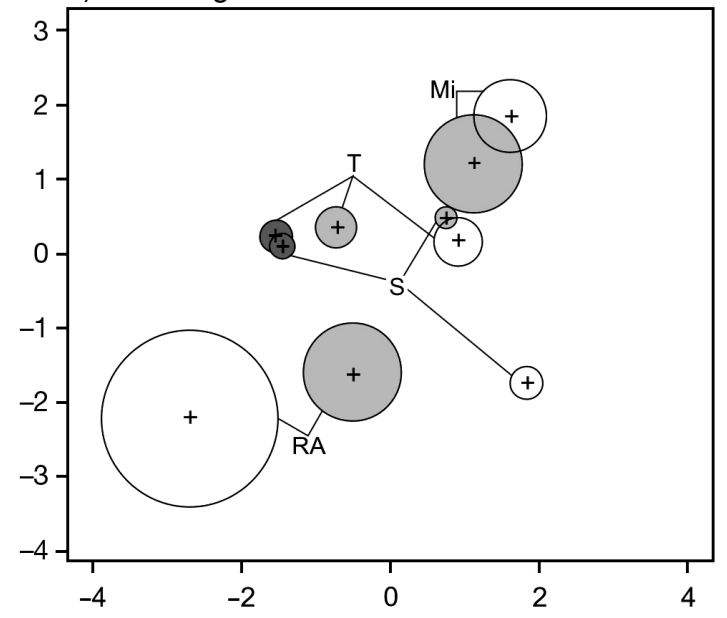

Canonical variate 1

Fig. 4. Canonical discriminant analysis summarizing variation in otolith elemental signatures of juvenile (a) Solea solea and (b) $S$. senegalensis in the estuarine systems along the Portuguese coast in May (dark grey), July (light grey) and October (white circles) 2009. Circle enclosures represent $95 \%$ confidence limits for the mean. See Table 1 for estuary abbreviations

estuary (up to 5 times the average) in both of the species and throughout the 2 sampling years (Fig. 2).

Seasonal variation in otolith elemental composition was significant in the 2 sole species (Table $3 b)$. In Solea solea, samples from later months (July and October) were generally similar and significantly different from the initial sampling month (May) (Fig. 4a). The separation on the first canonical variate was mainly driven by $\mathrm{Mn}$ :Ca ratios, and the second canonical variate was dominated by $\mathrm{Li}: \mathrm{Ca}$ and $\mathrm{Ba}: \mathrm{Ca}$ ratios. Seasonal variation was also observed for the otolith elemental signatures of $S$. senegalensis, particularly in the Tejo and Sado estuaries (Fig. 4b). Samples in these 2 estuaries showed little variation within months based on the small confidence ellipses, but mean canonical scores among months were dispersed throughout the CDA plot. In contrast, samples from Ria Aveiro and Mira occupied rather similar locations on the CDA plot in the 2 months that these locations were visited. Separation on the first 2 

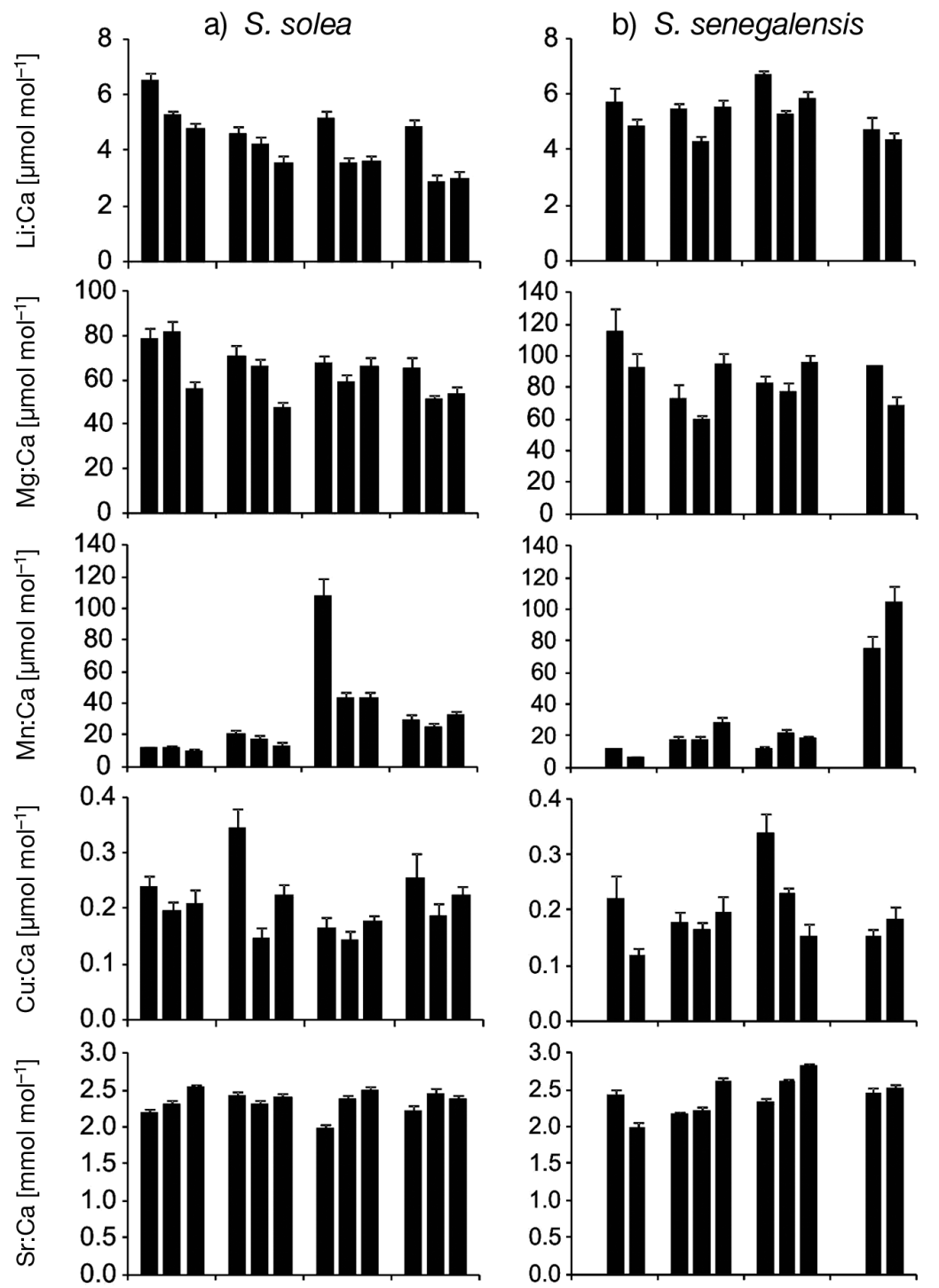

canonical variates was driven primarily by $\mathrm{Sr}: \mathrm{Ca}$ and $\mathrm{Mn}$ :Ca ratios, respectively. Some seasonal patterns were visible in the individual elemental ratios for $S$. solea (Fig. 5a), with Li:Ca values highest in May and diminishing over the following 2 months, while $\mathrm{Sr}$ :Ca showed the opposite pattern. Otolith elemental values for $S$. senegalensis showed no consistent seasonal patterns (Fig. 5b).

The CDA plot of elemental signatures of the 2 sole species in the estuaries where they co-occurred in 2009 indicated that variability among estuaries was larger than differences between species, with Solea solea and $S$. senegalensis grouped together for each of the 3 estuaries where these species co-occurred (Ria Aveiro, Tejo and Mira) (Fig. 6).

Finally, we examined the effectiveness of using elemental values in otoliths to accurately identify juvenile habitat residency using LDFA. Classification accuracy varied between the 2 years as well as between the 2 species (Table 4). Elemental values from Solea solea collected in 2006 did not satisfactorily classify the juveniles to the estuaries in which they were captured (overall cross-validated correct classification: $54 \%$ ) (Table $4 \mathrm{a}$ ). Based on the CDA plot of the estuaries in the 2 years of sampling (Fig. 3a), the northern and central estuaries (Douro, Ria Aveiro, Mondego and Tejo) were then pooled. The classification accuracy in the resulting LDFA for $S$. solea juveniles collected in 2006 improved to $80.1 \%$. In 2009, the overall cross-validated correct classification of individuals to the estuary where they were collected was $71.0 \%$. The highest classification accuracy was attained in the Mondego estuary, with $95.0 \%$ of the individuals correctly classified, and the Tejo estuary presented the lowest correct classifications, with $57.6 \%$ accuracy. Juveniles of $S$. senegalensis collected in 2006 were correctly classified to the estuary where they were collected with $71.6 \%$ accuracy (Table $4 \mathrm{~b}$ ). The

Fig. 5. Mean and standard error of element: Ca ratios ( $\mathrm{Li}, \mathrm{Mg}, \mathrm{Mn}, \mathrm{Cu}, \mathrm{Sr}$ $\mathrm{Pb}$ ) in otoliths of juvenile (a) Solea solea and (b) S. senegalensis in the estuarine systems sampled in May (M), July (J) and October (O) 2009. See Table 1 for estuary abbreviations 


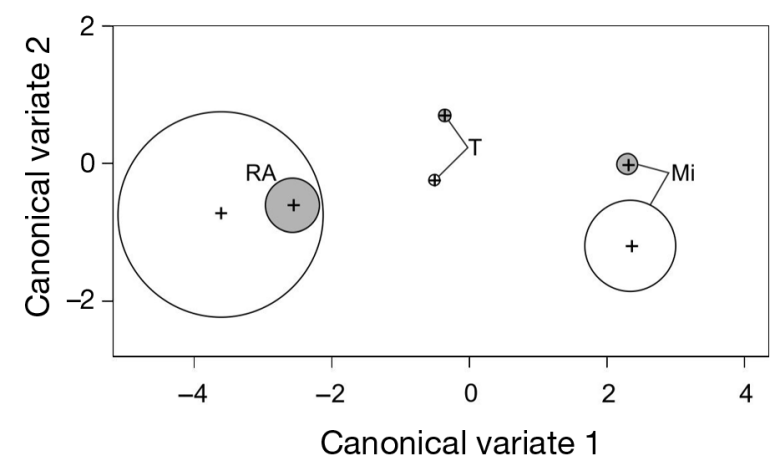

Fig. 6. Canonical discriminant analysis summarizing variation in otolith elemental signatures in the estuarine systems along the Portuguese coast where juvenile Solea solea (grey circles) and $S$. senegalensis (white circles) co-occur in 2009. Circle enclosures represent $95 \%$ confidence limits for the mean. See Table 1 for estuary abbreviations

highest accuracy was achieved for the Tejo estuary with $83.3 \%$, while $60.0 \%$ of the individuals from the Ria Aveiro estuary were correctly classified. In 2009, $72.9 \%$ of juvenile $S$. senegalensis were correctly classified to the estuary where they were collected. All of the individuals sampled from the Mira estuary were correctly assigned. The lowest classification accuracy was obtained in the Tejo estuary, with $62.7 \%$ of the juveniles correctly classified. Generally, the overall accuracy of the LDFA based on otolith elemental signatures varied considerably between years in $S$. solea juveniles. In contrast, while overall classification accuracy of juveniles of $S$. senegalensis did not differ much between years, the accuracy of the classification to individual estuaries varied. The Tejo estuary presented the highest classification accuracy in 2006 and the lowest in 2009. Similarly, Ria Aveiro had the lowest correct classification in 2006 and one of the highest in 2009.

\section{DISCUSSION}

Inter-annual variations in otolith geochemistry have been documented around the globe from freshwater to marine environments (Rooker et al. 2001, Kerr et al. 2007, Walther et al. 2008). Significant variability has also been documented at shorter time scales among months or seasons (Thorrold et al. 1998, Hamer et al. 2003, Patterson \& Kingsford 2005). Assessing temporal variation in otolith composition, at different scales, is of paramount importance when these values are used to constrain baseline data for connectivity studies (Gillanders 2002). We found that, while some of the estuaries along the Portuguese coast showed little inter-annual variation in terms of otolith composition, there was a significant overall effect of collection year. Knowledge of the inter-annual variation of elemental values in these 2 sole species will be particularly important if present data is to be used as a baseline to retrospectively determine the juvenile estuarine use of adults. In this case, the adults that are to be assigned to the estuaries must match the juveniles' year classes to determine the importance of different estuarine systems along the Portuguese coast.

We also found evidence of seasonal variation in the otolith composition of individuals sampled in the same estuary in May, July and October 2009. As with many marine migrants, Solea solea and S. senegalensis have protracted estuarine colonization periods, and a single year-class consists of several cohorts (Cabral 2003). Over this time, individuals may experience considerable environmental variation that may result in differences in the elemental composition of the otoliths. Seasonal variation in the elemental signatures of $S$. solea and $S$. senegalensis had a limited influence on the overall spatial separation of the estuaries analyzed in this study. However, the differences in otolith elemental signatures among these first months of estuarine use by the 2 sole species were significant. It therefore seems advisable to develop baseline values that incorporate short-term temporal variation to ensure that the signatures are representative of the year class. Samples should be based on juveniles of a year class collected at several occasions during the period of estuarine colonization. If juveniles are sampled at only one occasion, sampling should target individuals that are not all of the same size (Hamer et al. 2003).

The significant inter-annual and seasonal variability in otolith composition in this study likely reflects differences in the temperature, salinity and chemical composition of the water (reviewed by Elsdon et al. 2008). These parameters vary extensively in dynamic systems, such as estuaries. Water temperatures in the sampled estuarine systems along the Portuguese coast were generally higher in 2006 than 2009. No consistent pattern in salinity over the 2 sampling years was observed; however, precipitation was higher during 2006, especially in spring (Instituto de Meteorologia 2007, 2010). Higher precipitation rates potentially influence the chemical composition of the water due to higher freshwater input into estuaries. Monthly variation of temperature and salinity was also pronounced in 2009, with lowest values observed in May. Some of the elements analyzed 
Table 4. Cross-validated classification accuracy of discriminant function analysis of juvenile (a) Solea solea and (b) S. senegalensis in 2006 and 2009. Individuals were classified to an estuary based on otolith elemental signatures. Juveniles of $S$. solea sampled in 2006 in northern (Douro, Ria de Aveiro, Mondego) and central estuaries (Tejo) were pooled in Group North. Months were pooled within each year. Values in bold represent individuals correctly classified to the estuary of origin

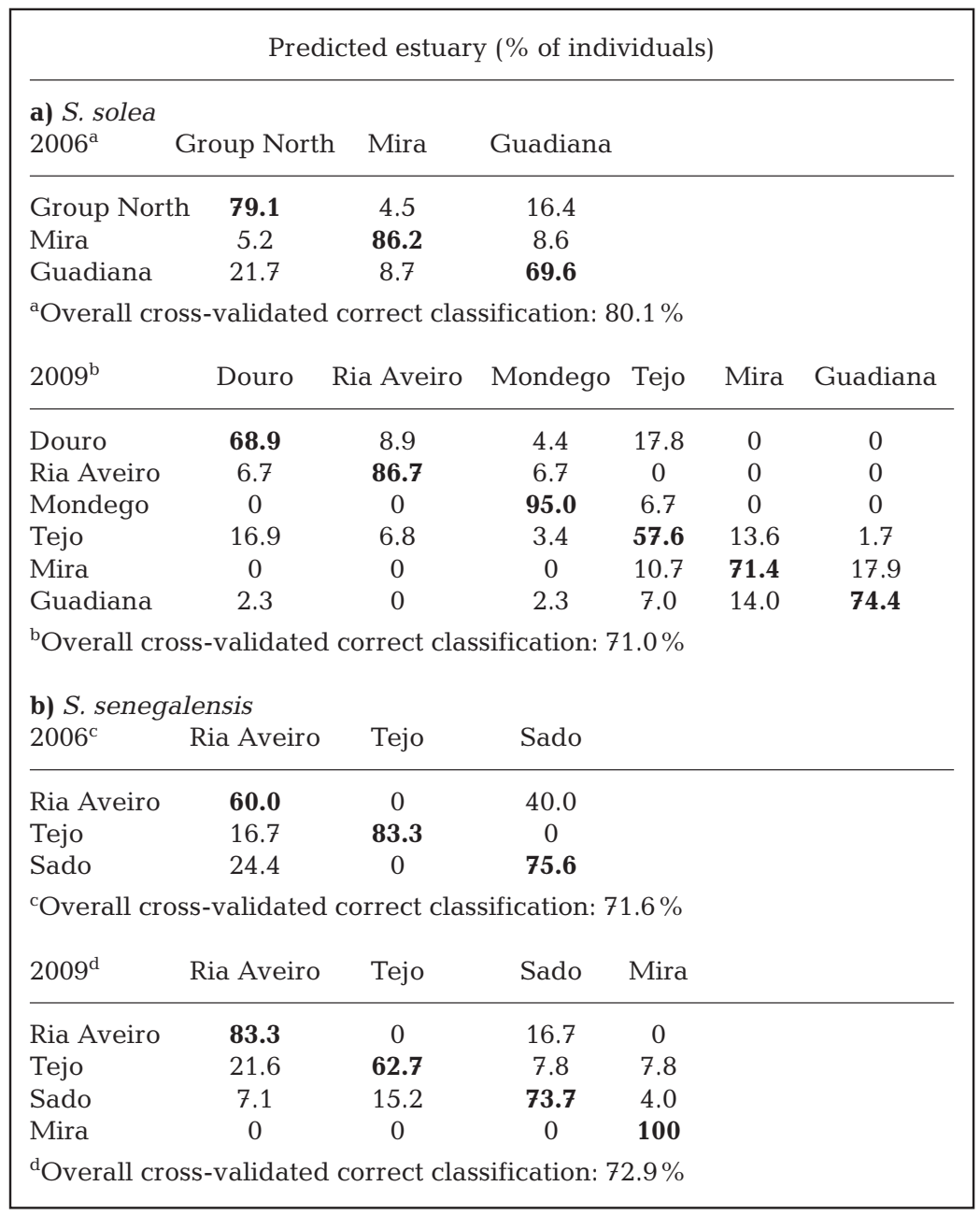

were found in the juvenile sole otoliths, the only functioning ironmanganese ore mine in Portugal is located a few $\mathrm{km}$ north of the Mira estuary (Cercal).

Consistent and negatively correlated patterns in $\mathrm{Li}: \mathrm{Ca}$ and $\mathrm{Sr}: \mathrm{Ca}$ ratios from Solea solea juveniles were found. Ambient Sr:Ca levels are often highly correlated with otolith $\mathrm{Sr}: \mathrm{Ca}$ (e.g. Bath et al. 2000, Elsdon \& Gillanders 2003). However, the non-linear mixing profiles of $\mathrm{Sr}$ and $\mathrm{Ca}$ ions in estuaries implies that this pattern was not a function of variable $\mathrm{Sr}$ : Ca ratios in the ambient water. A previous study of otolith elemental signatures of this species conducted in the same estuaries similarly found no correlation between Sr:Ca and salinity (Tanner et al. 2011). Temperature has been shown to affect Sr incorporation into otoliths positively, particularly at temperatures around $20^{\circ} \mathrm{C}$ (e.g. Elsdon \& Gillanders 2004, Martin et al. 2004). A response of otolith chemistry to increases in water temperatures in the estuaries from late spring to late summer therefore provides the most likely explanation for the Sr:Ca patterns. If this explanation is accurate, the observation that Li:Ca and $\mathrm{Sr}: \mathrm{Ca}$ were negatively correlated suggests that Li:Ca ratios in otoliths may be negatively correlated with temperature. However, very little is known about the factors influencing $\mathrm{Li}: \mathrm{Ca}$ ratios in otoliths, even though $\mathrm{Li}$ is

notably varied spatially or temporally at the scales examined. The fact that $\mathrm{Mn}: \mathrm{Ca}$ ratios were lower in 2006 than 2009 in the otoliths of both species of sole suggest that the difference was caused by an environmental factor related either directly (e.g. dissolved Mn:Ca ratios in ambient waters) or indirectly (e.g. through an effect of temperature on $\mathrm{Mn}: \mathrm{Ca}$ ratios in otoliths of both species) to otolith composition. Similarly, the consistently high $\mathrm{Mn}$ :Ca ratios observed in the Mira estuary in both species and sampling years, as well as in an otolith chemistry study conducted in 2005 (Vasconcelos et al. 2007b), suggests that juveniles are exposed to elevated dissolved Mn:Ca levels in the estuary. While we can only speculate as to the source of the Mn ions that often included in the suite of elements used in otolith chemistry studies (Brown 2006). While it remains to be seen if indeed Li:Ca may be a useful proxy for temperature, understanding what are likely complex mechanisms underlying element incorporation into otoliths is not required to use elemental differences in otoliths as estuary-specific natural tags (Thorrold et al. 1998).

The results obtained confirm that otolith geochemistry in juvenile Solea solea and S. senegalensis are suitable natural markers to discriminate estuaries along the Portuguese coast and identify the nursery origin of adults, as suggested by Vasconcelos et al. (2007b, 2008). In addition, otolith compositions of $S$. solea have been successfully used to distinguish 
estuarine and coastal areas in the Thames estuary (Leakey et al. 2009) and to discriminate among 4 known nursery areas in the North Sea (Cuveliers et al. 2010). However, none of these studies assessed the temporal variation of otolith chemistry. The large differences observed in classification accuracy of juveniles of $S$. solea collected in 2006 and 2009 demonstrate that some years produce stronger spatial differences in elemental signatures than others. Moreover, elemental ratios in otoliths from an estuary may show strong spatial differences from the other estuaries in one year and have spatially similar signatures in another year, as observed in the elemental signatures of juvenile $S$. senegalensis in the Tejo estuary. These data highlight the observation that the application of otolith elemental signatures in assessing the importance of juvenile nursery habitats to adult populations is a 2-step process (Cook 2011). First, otolith geochemistry of juveniles must show spatial differences among the estuaries of interest. Second, adult fish that match the juvenile year-class of the baseline data are then compared to the juvenile baseline data. The elemental values in otoliths of the 2 sole species assayed in this study constitute the baseline data for the future assessment of movements between juvenile and adult populations.

The comparison of elemental signatures of the 2 sole species in the estuaries where they co-occurred also evidenced the strong spatial variation, particularly in 2009. Otolith elemental signatures have been shown to be species specific (Swearer et al. 2003), and only some similarities may exist among species with close phylogeny and ecology (Reis-Santos et al. 2008). Still, spatial differences in the otolith elemental signatures of Solea solea and S. senegalensis among the estuaries outweighed the species-specific variation.

Flatfish fisheries are widely spread along the Portuguese coast and play an important socio-economic role (Teixeira \& Cabral 2009). Although flatfishes account for $<4 \%$ of the total fish biomass landed, these species, and particularly soles, account for almost $11 \%$ of the economic value of the landings (Directorate-General of Fisheries and Aquaculture, DGPA; www.dgrm.min-agricultura.pt). The importance of soles to small-scale fisheries in Portuguese waters and the increasing fishing pressures on these stocks call for a more holistic understanding of the ecology of these species. In particular, knowledge of the population structure and exchange rates among spatially separated subpopulations of juveniles and adults is essential for the development of effective fisheries management plans and conservation strategies.
Acknowledgements. We thank all involved in the fish sampling and S. Birdwhistell for help in sample analysis. This study was funded by the 'Fundação para a Ciência e a Tecnologia' (FCT), PEst-OE/MAR/UI0199/2011. S.E.T. was funded by a PhD grant from FCT (SFRH/BD/ 40313/ 2007).

\section{LITERATURE CITED}

Bath GE, Thorrold SR, Jones CM, Campana SE, McLaren JW, Lam JWH (2000) Strontium and barium uptake in aragonitic otoliths of marine fish. Geochim Cosmochim Acta 64:1705-1714

Brown JA (2006) Using the chemical composition of otoliths to evaluate the nursery role of estuaries for English sole Pleuronectes vetulus populations. Mar Ecol Prog Ser 306: 269-281

Cabral H (2003) Differences in growth rates of juvenile Solea solea and Solea senegalensis in the Tagus estuary, Portugal. J Mar Biol Ass UK 83:861-868

Cabral HN, Vasconcelos RP, Vinagre C, França S and others (2007) Relative importance of estuarine flatfish nurseries along the Portuguese coast. J Sea Res 57:209-217

Campana SE (1999) Chemistry and composition of fish otoliths: pathways, mechanisms and applications. Mar Ecol Prog Ser 188:263-297

> Clarke LM, Walther BD, Munch SB, Thorrold SR, Conover DO (2009) Chemical signatures in the otoliths of a coastal marine fish, Menidia menidia, from the northeastern United States: spatial and temporal differences. Mar Ecol Prog Ser 384:261-271

Cook GS (2011) Changes in otolith microchemistry over a protracted spawning season influence assignment of natal origin. Mar Ecol Prog Ser 423:197-209

Cowen RK, Gawarkiewicz G, Pineda J, Thorrold SR, Werner FE (2007) Population connectivity in marine systems: an overview. Oceanography 20:14-21

Cuveliers EL, Geffen AJ, Guelinckx J, Raeymaekers JAM, Skadal J, Volckaert FAM, Maes GE (2010) Microchemical variation in juvenile Solea solea otoliths as a powerful tool for studying connectivity in the North Sea. Mar Ecol Prog Ser 401:211-220

Elsdon TS, Gillanders BM (2003) Relationship between water and otolith elemental concentrations in juvenile black bream Acanthopagrus butcheri. Mar Ecol Prog Ser 260:263-272

> Elsdon TS, Gillanders BM (2004) Fish otolith chemistry influenced by exposure to multiple environmental variables. J Exp Mar Biol Ecol 313:269-284

- Elsdon TS, Wells BK, Campana SE, Gillanders BM and others (2008) Otolith chemistry to describe movements and life-history parameters of fishes: hypotheses, assumptions, limitations and inferences. Oceanogr Mar Biol Annu Rev 46:297-330

> Fairclough DV, Edmonds JS, Lenanton RCJ, Jackson G, Keay IS, Crisafulli BM, Newman SJ (2011) Rapid and cost-effective assessment of connectivity among assemblages of Choerodon rubescens (Labridae), using laser ablation ICP-MS of sagittal otoliths. J Exp Mar Biol Ecol 403:46-53

Gillanders BM (2002) Temporal and spatial variability in elemental composition of otoliths: implications for determining stock identity and connectivity of populations. Can J Fish Aquat Sci 59:669-679 
Gillanders BM, Able KW, Brown JA, Eggleston DB, Sheridan PF (2003) Evidence of connectivity between juvenile and adult habitats for mobile marine fauna: an important component of nurseries. Mar Ecol Prog Ser 247:281-295

Hamer PA, Jenkins GP, Gillanders BM (2003) Otolith chemistry of juvenile snapper Pagrus auratus in Victorian waters: natural chemical tags and their temporal variation. Mar Ecol Prog Ser 263:261-273

Hamer PA, Jenkins GP, Coutin P (2006) Barium variation in Pagrus auratus (Sparidae) otoliths: a potential indicator of migration between an embayment and ocean waters in south-eastern Australia. Estuar Coast Shelf Sci 68: 686-702

Instituto de Meteorologia (2007) Instituto de Meteorologia, Caracterização climática ano 2006. Technical Report, Ministério da Ciência Tecnologia e Ensino Superior, Lisbon

Instituto de Meteorologia (2010) Instituto de Meteorologia, Boletim climatológico anual - ano 2009. Technical Report, Ministério da Ciência Tecnologia e Ensino Superior, Lisbon

Kerr LA, Secor DH, Kraus RT (2007) Stable isotope $\left(\delta^{13} \mathrm{C}\right.$ and $\delta^{18} \mathrm{O}$ ) and $\mathrm{Sr} / \mathrm{Ca}$ composition of otoliths as proxies for environmental salinity experienced by an estuarine fish. Mar Ecol Prog Ser 349:245-253

Koutsikopoulos C, Desaunay Y, Dorel D, Marchand J (1989) The role of coastal areas in the life history of sole (Solea solea L.) in the Bay of Biscay. Sci Mar 53:567-575

> Leakey CDB, Attrill MJ, Fitzsimons MF (2009) Multi-element otolith chemistry of juvenile sole (Solea solea), whiting (Merlangius merlangus) and European seabass (Dicentrarchus labrax) in the Thames Estuary and adjacent coastal regions. J Sea Res 61:268-274

Marchand J (1991) The influence of environmental conditions on settlement, distribution and growth of 0-group sole (Solea solea (L.)) in a macrotidal estuary (Vilaine, France). Neth J Sea Res 27:307-316

Martin GB, Thorrold SR, Jones CM (2004) Temperature and salinity effects on strontium incorporation in otoliths of larval spot (Leiostomus xanthurus). Can J Fish Aquat Sci 61:34-42

> Patterson HM, Kingsford MJ (2005) Elemental signatures of Acanthochromis polyacanthus otoliths from the Great Barrier Reef have significant temporal, spatial, and between-brood variation. Coral Reefs 24:360-369

Quéro JC, Dessouter M, Lagardère F (1986) Soleidae. In: Whitehead P, Bauchot ML, Hureau JC, Nielsen J, Tortonese $\mathrm{E}$ (eds) Fishes in the North-Eastern Atlantic and the Mediterranean. UNESCO, Paris, p 1308-1342

Ramos J (1982) Contribuición al estudio de la sexualidad del lenguado, Solea solea (Linneo, 1758) (Pisces, Soleidae). Investig Pesq 46:275-286

Reis-Santos P, Vasconcelos RP, Ruano M, Latkoczy C, Günther D, Costa MJ, Cabral HN (2008) Interspecific variations of otolith chemistry in estuarine fish nurseries. J Fish Biol 72:2595-2614

Rooker JR, Secor DH, Zdanowicz VS, Itoh T (2001) Discrimination of northern bluefin tuna from nursery areas in the

Editorial responsibility: Hans-Heinrich Janssen, Oldendorf/Luhe, Germany
Pacific Ocean using otolith chemistry. Mar Ecol Prog Ser 218:275-282

Sturgeon RE, Willie SN, Yang L, Greenberg R and others (2005) Certification of a fish otolith reference material in support of quality assurance for trace element analysis. J Anal At Spectrom 20:1067-1071

Swearer SE, Forrester GE, Steele MA, Brooks AJ, Lea DW (2003) Spatio-temporal and interspecific variation in otolith trace-elemental fingerprints in a temperate estuarine fish assemblage. Estuar Coast Shelf Sci 56: 1111-1123

- Tanner SE, Vasconcelos RP, Reis-Santos P, Cabral HN, Thorrold SR (2011) Spatial and ontogenetic variability in the chemical composition of juvenile common sole (Solea solea) otoliths. Estuar Coast Shelf Sci 91:150-157

Teixeira CM, Cabral HN (2009) Time series analysis of flatfish landings in the Portuguese coast. Fish Res 96: 252-258

Thorrold SR, Jones CM, Campana SE, McLaren JW, Lam JWH (1998) Trace element signatures in otoliths record natal river of juvenile American shad (Alosa sapidissima). Limnol Oceanogr 43:1826-1835

Thorrold SR, Latkoczy C, Swart PK, Jones CM (2001) Natal homing in marine fish metapopulation. Science 291: 297-299

Thorrold SR, Jones GP, Hellberg ME, Burton RS and others (2002) Quantifying larval retention and connectivity in marine populations with artificial and natural markers. Bull Mar Sci 70:291-308

Thorrold SR, Zacherl DC, Levin LA (2007) Population connectivity and larval dispersal using geochemical signatures in calcified structures. Oceanography 20:80-89

> Thresher RE, Procter CH (2007) Population structure and life history of orange roughy (Hoplostethus atlanticus) in the SW Pacific: inferences from otolith chemistry. Mar Biol 152:461-473

> Vasconcelos RP, Reis-Santos P, Fonseca V, Maia A and others (2007a) Assessing anthropogenic pressures on estuarine fish nurseries along the Portuguese coast: a multimetric index and conceptual approach. Sci Total Environ $374: 199-215$

> Vasconcelos RP, Reis-Santos P, Tanner S, Fonseca V and others (2007b) Discriminating estuarine nurseries for five fish species through otolith elemental fingerprints. Mar Ecol Prog Ser 350:117-126

- Vasconcelos RP, Reis-Santos P, Tanner S, Maia A and others (2008) Evidence of estuarine nursery origin of five coastal fish species along the Portuguese coast through otolith elemental fingerprints. Estuar Coast Shelf Sci 79:317-327

> Vasconcelos RP, Reis-Santos P, Maia A, Fonseca V and others (2010) Nursery use patterns of commercially important marine fish species in estuarine systems along the Portuguese coast. Estuar Coast Shelf Sci 86:613-624

Walther BD, Thorrold SR, Olney JE (2008) Geochemical signatures in otoliths record natal origins of American shad. Trans Am Fish Soc 137:57-69

Yoshinaga J, Nakama A, Morita M, Edmonds JS (2000) Fish otolith reference material for quality assurance of chemical analyses. Mar Chem 69:91-97

Submitted: September 30, 2011; Accepted: January 25, 2012 Proofs received from author(s): April 17, 2012 